\title{
Working
}

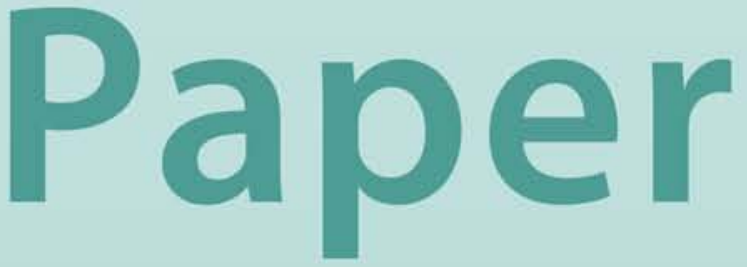




\section{Quantity Controls, License Transferability and the Level of Investment}

Kala Krishna, Ling Hui Tan, and Ram Ranjan 


\title{
IMF Working Paper
}

IMF Institute

\section{Quantity Controls, License Transferability, and the Level of Investment}

\author{
Prepared by Kala Krishna, Ling Hui Tan, and Ram Ranjan ${ }^{1}$ \\ Authorized for distribution by Eric V. Clifton
}

December 2001

\begin{abstract}
The views expressed in this Working Paper are those of the author(s) and do not necessarily represent those of the IMF or IMF policy. Working Papers describe research in progress by the author(s) and are published to elicit comments and to further debate.
\end{abstract}

This paper models investment/entry decisions in a competitive industry that is subject to a quantity control on an input for production. The quantity control is implemented by auctioning licenses for the restricted input (e.g., a pollution permit or a production license). The paper shows that liberalizing the quantity control could reduce investment in the industry under certain circumstances. Furthermore, the level of investment is quite different when licenses are tradable than when they are not. Key factors in the comparison include the elasticity of demand for the final good and the degree of input substitutability. Two examples are computed to illustrate the results.

JEL Classification Numbers:D45, D21, F13, L51

Keywords: Quotas; licensing; transferability; tradable quotas; entry; investment

Author’s E-Mail Address:kmk4@psu.edu; ltan@imf.org; rxr229@psu.edu

\footnotetext{
${ }^{1}$ Kala Krishna and Ram Ranjan are at Pennsylvania State University. This paper was written while Kala Krishna was a visiting scholar at the IMF Institute. We are grateful to Andrew Feltenstein for helpful comments.
} 


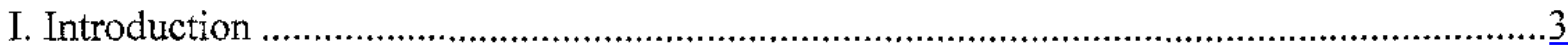

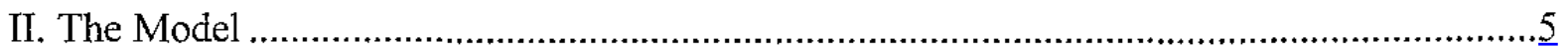

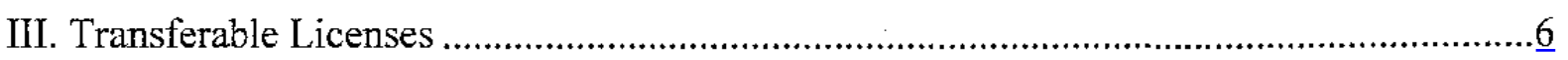

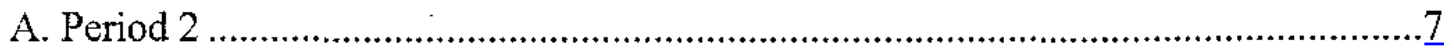

License market clearing ...............................................................................

Product market clearing …….....................................................................

B. Period 1 ................................................................................................

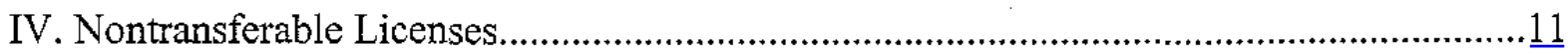

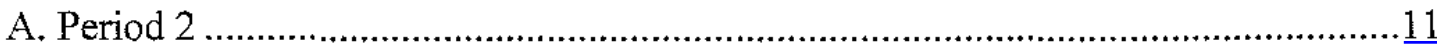

Product market clearing .............................................................................11

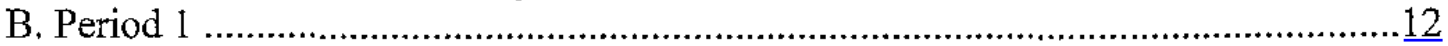

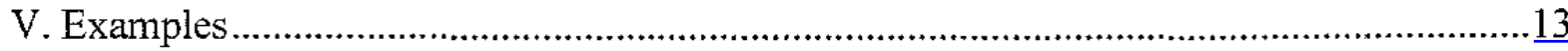

A. Cobb Douglas Production Function................................................................13

B. Fixed Coefficients Production Function .............................................................16

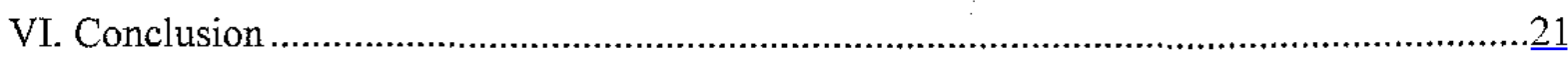

Appendices

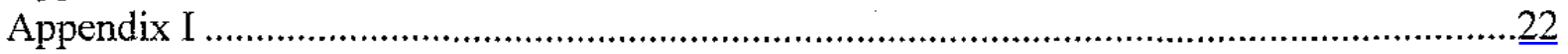

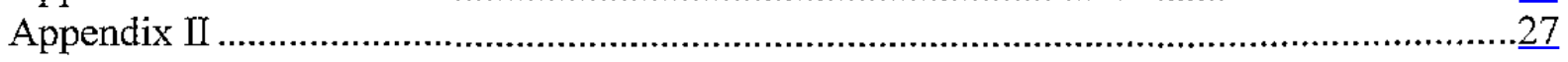

Figures

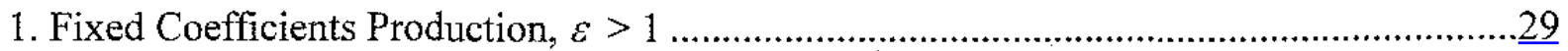

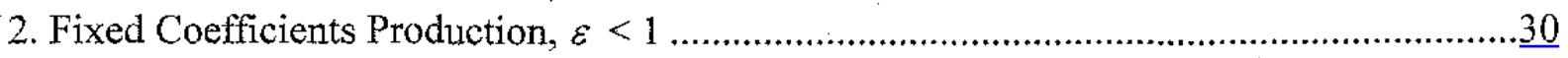

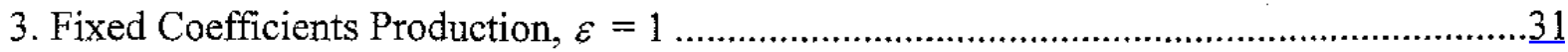

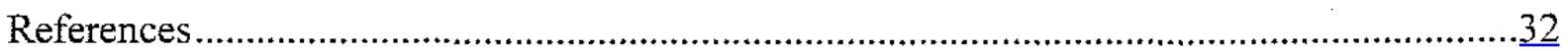




\section{INTRODUCTION}

Quantity controls on production inputs are commonly used throughout the world. In transition countries, input rationing is still prevalent in many industries. In some developing countries, import licensing and foreign exchange controls may restrict the quantity of inputs available to domestic firms. In industrial countries, input quantity controls are often used to regulate natural resource industries such as timber and fishing; they have also been imposed in response to supply shocks such as those experienced with petroleum or electricity, and for environmental reasons such as pollution reduction.

Input rationing is usually implemented by issuing licenses or permits for the restricted factor. In this regard, for analytical purposes, there is a close similarity between input quotas and output quotas: in the latter case, a license is required in order to produce a certain amount of output, so the license can be thought of as a restricted input that is necessary for production.

The initial allocation of licenses may be based upon certain criteria, such as firms' historical performance, or by auction. In some cases, these licenses are tradable; in other cases, they are not. This is a particularly important issue in agricultural and natural resource economics, where production controls are most likely to be implemented. For example, in fisheries management, some countries-notably Iceland and New Zealand-have introduced a system of individual transferable quotas (ITQ) whereby an annual quota for a particular species (the total allowable catch) is distributed among individual firms by means of licenses that are tradable; other countries--such as the United States and the United Kingdom-are still weighing the merits of this system vis-à-vis alternative measures such as nontransferable individual fishing quotas. Similarly, in the dairy and poultry industry, there is an ongoing discussion within the United States and the European Union on the advantages of a supply management system like Canada's, where farmers have to purchase a tradable permit to produce a specified amount of output.

Although they are widely used, quantity controls and input rationing have not been widely studied. Squires (1994) estimates the effect of an input quantity control on factor demand, output supply, and capacity utilization by a competitive multiproduct firm in a certain environment, using data on wet rice production in Indonesia. However, there has been little work on the effect of input rationing on entry and investment in the affected industries under production uncertainty. This paper considers the investment/entry decision in a competitive industry with no fixed costs which is subject to input rationing such that licenses or permits are required for production. The objective is to compare the level of investment in the industry under two scenarios: when the licenses are transferable and when the licenses are nontransferable. A similar problem is analyzed in Spencer (1997), which considers the effects of a licensing requirement on imported capital equipment, comparing the outcome under an exogenous bureaucratic allocation (nontransferable quota licenses) with that under a market allocation (transferable licenses). Unlike Spencer (1997), however, the analysis used in this paper draws on the model(s) developed in Krishna and Tan (1999), which compares the endogenous outcomes from transferable and nontransferable regimes of quota licenses. 
They show that - contrary to the common belief that transferable licenses are always worth more than nontransferable licenses and always yield more efficient outcomes--the price of transferable licenses can fall below the price of nontransferable licenses if the quota is sufficiently large and that nontransferability could result in higher welfare if license revenue is heavily weighted in the overall welfare function. To the extent that license possession enables a firm to produce the final product, the license market will be closely linked to the market for the final product. This paper thus extends the analysis in Krishna and Tan (1999) by explicitly modeling the product market as well. In this paper, the demand for licenses (i.e., the restricted input) is modeled as a derived demand arising from production in a final output market. It is assumed that each firm has to utilize a certain number of licenses in order to produce a unit of output.

It is necessary to introduce an element of uncertainty into the model in order to make a meaningful comparison between transferable and nontransferable licenses. After all, as explained in Krishna and Tan (1999), if every economic agent knows with full certainty his or her valuation of a license at all times, and if the initial allocation of licenses is determined endogenously (reflecting the voluntary choice of each agent), then there will be no scope for resale and transferability will confer no benefit (or equivalently, nontransferability will imply no cost). ${ }^{2}$ Furthermore, this uncertainty has to be at the individual rather than the aggregate level: if all agents faced a common shock then, again, there will be no scope for resale and no benefit from transferability. In this paper, uncertainty is modeled as a firm-specific productivity shock which affects the efficiency of final good production. Firms have to purchase licenses for production before this productivity shock is realized; in the transferable regime, they may (re-)trade (buy or sell) their licenses after the uncertainty is resolved but in the nontransferable regime, they may not.

There are several papers that analyze a competitive industry with free entry under uncertainty. (See, Sandmo (1971), Batra and Ullah (1974), Hartman (1976), Appelbaum and Katz (1986), and Haruna (1992), for example.) However, this literature focuses on the effect of uncertainty on output, entry, and factor demand under different assumptions regarding the degree of firms' risk aversion; it does not address input constraints or license transferability. There is also an existing literature on the effect of uncertainty on investment in a competitive industry. (See Caballero (1991) and Pindyck (1993), for example.) However, the focus of this literature is on investment irreversibility and not on license transferability. Also, in almost all cases, the uncertainty modeled takes the form of industry-wide uncertainty (e.g., market demand or price uncertainty) rather than idiosyncratic (firm-level) uncertainty.

\footnotetext{
${ }^{2}$ In many practical applications, the initial allocation of licenses is not endogenous. For example, the initial allocation of tradable fishing quotas in New Zealand and Iceland were not effected by auction but by free distribution to existing firms based primarily on historical catch (see OECD (1999)). However, such schemes are generally considered inferior to market-based mechanisms such as allocation by auction, on efficiency and equity grounds (see Morgan (1997), for example.)
} 
The rest of the paper is organized as follows. Section II sets up the basic model to be used for the analysis. Section III solves the model for the level of investment under transferability. Section IV does the same for nontransferability and compares the results with those obtained in Section III. Section V presents two examples using a Cobb-Douglas production function and a fixed coefficients production function. Section VI concludes.

\section{THE MODEL}

The analysis that follows makes use of a partial equilibrium setting which focuses on the market for licenses and the related market for the final good that is produced using the licenses. As mentioned earlier, the demand for licenses is essentially a derived demand for an input, hence it is important to model the license market as a secondary market that is linked to the product market where the primary activity of the firms takes place. It is assumed that both markets are perfectly competitive.

The timing of events is as follows. In Period 1, firms decide whether to enter the industry (invest a unit of capital, $K$ ) at a cost of $r$ per unit of capital. Upon entry, they buy licenses $(Z)$ which are needed for production later. In Period 2, they realize their actual productivity and produce output. If the licenses are transferable, they may also buy and sell licenses at this point; if the licenses are nontransferable, they cannot use more than what they purchased in Period 1.

Assume that the final good is produced using a constant returns to scale production function $F(K, Z)$, using capital and licenses as inputs. The usual Inada conditions are assumed to be satisfied, i.e., the marginal product of an input is decreasing, tends to zero as the input tends to infinity, and tends to infinity as the input tends to zero. Firms differ according to productivity, indexed by $\beta$, where $\beta$ is a random variable distributed as $h(\beta)$. One may consider, for example, a competitive agricultural industry that faces a quantity restriction on farm equipment or agrochemical inputs: all farms utilize the same technology but their output (harvest) may differ due to random effects such as weather and soil conditions.

Since the production function is characterized by constant returns to scale, $K$ can be interpreted as the total number of firms in the industry, with $K=1$ for each firm. Hence $K$ denotes both the level of investment as well as the level of entry. In what follows, the terms "investment" and "entry" will be used interchangeably.

The output of any given firm is:

$$
\begin{aligned}
& q=\beta F(1, z)=\beta f(z), \\
& f_{z}(z)>0, \quad f_{z z}(z)<0
\end{aligned}
$$


where $z$ denotes the firm's license input, $f(z)$ is the intensive form of $F(1, z)$, and subscripts denote partial derivatives. This form is equivalent to random Hicks-neutral technical change. Firms with high realizations of $\beta$ have a higher total factor productivity than firms with low realizations of $\beta$. In the agricultural example given above, farms with low realizations of $\beta$ will have poor harvests; those with high realizations of $\beta$ will have good harvests.

The ex ante distribution of $\beta$ is the same for all firms, although their ex post realizations will not be the same. Since there is a continuum of firms, and assuming that $\beta$ is independently and identically distributed, the ex ante distribution of $\beta$ for each firm can be interpreted as being the same as the ex post distribution of realizations of $\beta$ across all firms in the industry. ${ }^{3}$

Demand for the final product is denoted by $D(P)$, where $D_{P}(P)<0$. The number of licenses available for sale (i.e., the quota level for the restricted input) is assumed to be exogenously set by the government. This is denoted by $\bar{Z}$. In the case of input quotas, possession of a license gives a firm the right to use a specified amount of the restricted input; in the case of output quotas, possession of a license gives a firm the right to produce a specified amount of the restricted output.

\section{Transferable LiCENSES}

Consider first the case of transferable licenses. This means that although the firms must purchase licenses from the government before knowing $\beta$, they may freely trade their licenses after $\beta$ is realized, that is, they may re-optimize their license allocation ex post. Effectively, therefore, the timing of the actions is as follows:

1) In Period 1, the level of investment (or the number of firms), $K$, is determined through free entry and exit, given the exogenously determined quota level, $\bar{Z}$. Only the distribution of $\beta, h(\beta)$, is known at this stage.

2) In Period 2, $\beta$ is realized, i.e., each firm faces a (different) productivity shock. At this time, the industry demand for licenses is determined, given $K, \beta$, and $\bar{Z}$, and production takes place. Hence the license market and the product market clear in Period 2.

\footnotetext{
${ }^{3}$ Judd (1985) points out some technical issues in deriving this result.

${ }^{4}$ Returning to the agricultural example, one may consider, for instance, a quota on capital equipment for harvesting or a quota on pre-harvest insecticides: farms with low realizations of $\beta$ (poor harvests) will demand less of the restricted input than those with high realizations of $\beta$ (good harvests).
} 
The model is solved backwards, beginning with Period 2.

\section{A. Period 2}

Consider an individual firm's production function given by Equation (1). In Period 2, the firm has already invested 1 unit of capital and knows what its realization of $\beta$ is. Hence it will demand licenses up to the point where the value of the marginal product of a license is equal to the price of a license, denoted by $v$ :

$$
P \beta f_{z}(z)=v
$$

Equation (2) implicitly defines the firm's demand for licenses, $z^{T}(\beta, v, P)$ :

$$
z^{T}(\beta, v, P)=f_{z}^{-1}\left(\frac{v}{\beta P}\right)
$$

As long as the Inada conditions are met, all firms will demand some licenses. Note that $z_{\beta}^{T}(\beta, v, P)>0$, i.e., at any given license and product price, furms with a higher productivity will demand more licenses as their marginal product of a license is higher. Note also that $z_{v}^{T}(\beta, v, P)<0$, i.e., an increase in the license price will reduce the demand for licenses (for a given product price and productivity realization), and $z_{P}^{T}(\beta, v, P)>0$, i.e., an increase in the product price will raise the demand for licenses (for a given license price and productivity realization).

\section{License market clearing}

Given the total number of licenses, $\bar{Z}$, the license market clears when the industry's demand for licenses is equal to $\bar{Z}$ :

$$
\bar{Z}=K \int_{\beta} z^{T}(\beta, v, P) h(\beta) d \beta=K \int_{\beta} f_{z}^{-1}\left(\frac{v}{\beta P}\right) h(\beta) d \beta
$$

Equation (4) implicitly defines the license price, $v^{T}(P, K ; \bar{Z})$ :

$$
v^{T}(P, K ; \bar{Z})=P \cdot g\left(\frac{\bar{Z}}{K}\right)
$$

Note that $v^{T}(P, K ; \bar{Z})$ is increasing in both endogenous variables, i.e., $v_{P}^{T}(P, K ; \bar{Z})>0$ and $v_{K}^{T}(P, K ; \bar{Z})>0$, and decreasing in the exogenous variable: $v_{\bar{Z}}^{T}(P, K ; \bar{Z})<0$. For any given $K$ and $\bar{Z}$, an increase in the product price, $P$, will increase 
the demand for licenses (as noted earlier) so the license price, $v$, will have to rise to maintain the equality between license demand and supply. In fact, it can be seen from Equation (2) that $v$ varies one-for-one with $P$ so that a doubling of the product price will lead to a doubling of the license price. For any given $P$ and $\bar{Z}$, an increase in investment (or the number of firms), $K$, will increase the demand for licenses through the scale effect so the license price, $v$, will have to rise to maintain the equality between license demand and supply. For any given $P$ and $K$, an increase in the supply of licenses, $\bar{Z}$, will reduce the license price, $v$.

Thus, output of a firm with realization $\beta$ is $\beta f\left(z^{T}\left(\beta, v^{T}(P, K ; \bar{Z}), P\right)\right)$, and industry output is:

$$
Q^{T^{T}}(K ; \bar{Z})=K \int_{\beta} \beta f\left(z^{T}\left(\beta, v^{T}(P, K ; \bar{Z}), P\right)\right) h(\beta) d \beta
$$

Lemma $1: Q_{K}^{T}(K ; \bar{Z})>0$ and $Q_{\bar{Z}}^{T}(K ; \bar{Z})>0$

Proof: See Appendix I for the proof.

The intuition behind the first result is as follows. By concavity of the production function, the marginal product of $z$ is decreasing in $z$ and lies below the average product of $z$. As shown in (5), $v^{T}$ rises as $K$ rises, for any given $P$ and $\bar{Z}$. This increase in $v^{T}$ induces each firm to use less $z$, thereby raising the average product of $z$. Since the total amount of licenses used is fixed at $\bar{Z}$, total output must rise as a result.

\section{Product market clearing} demand:

The product market clears when aggregate supply of the final good equals aggregate

$$
D(P)=Q^{T}(K ; \bar{Z})
$$

Equation (7) gives the equilibrium product price as a function of $K$ and $\bar{Z}$ :

$$
P^{T}(K ; \bar{Z})=D^{-1}\left(Q^{T}(K ; \bar{Z})\right)
$$

From Lemma 1 , it follows that $P_{K}^{T^{\prime}}(K ; \bar{Z})<0$ and $P_{\bar{Z}}^{T}(K ; \bar{Z})<0$. For any given $\bar{Z}$, an increase in $K$ increases the supply of the product, driving down the product price.

Using Equations (5) and (8), the equilibrium license price can also be written as a function of $K$ and $\bar{Z}$ : 


$$
v^{T}(K ; \bar{Z})=D^{-1}\left(Q^{T}(K ; \bar{Z})\right) \cdot g\left(\frac{\bar{Z}}{K}\right)
$$

Lemma 2: $v_{\bar{Z}}^{T}(K ; \bar{Z})<0$ but the sign of $v_{K}^{T}(K ; \bar{Z})$ is ambiguous.

Proof: See Appendix I for the proof.

For the second result, note that there are two effects on $v^{T}(K ; \bar{Z})$ of an increase in $K$ for a given $\bar{Z}$. The first (scarcity) effect makes licenses relatively more scarce and hence raises the license price, $v$. The second (output) effect operates through $P^{T}(K ; \bar{Z}):$ an increase in $K$ increases supply of the final product, reducing the product price, and thereby reducing $v$. Since the two effects work in opposite directions, $v^{T}(K ; \bar{Z})$ could be increasing or decreasing in $K$. It is likely to be decreasing in $K$ when the output effect predominates, i.e., when $K$ and $Z$ are easily substitutable in production and/or when demand for the final good is very inelastic (so that a small increase in output induced by an increase in $K$ requires a large fall in price). It is likely to be increasing in $K$ when the scarcity effect predominates, i.e., when $K$ and $Z$ are not easily substitutable and/or demand for the final good is very elastic.

\section{B. Period 1}

In Period 1, entry and exit of firms will determine the total level of investment (or industry size), $K$. The industry will be in equilibrium-i.e., there will be no further entry or exit-when the expected profit from an additional unit of capital is zero. Let $r$ denote the unit cost of capital. Since all firms are ex ante identical, zero expected profit for an individual firm is the same as zero aggregate profits. The zero-profit condition can thus be written as:

$$
P^{T}(K ; \bar{Z}) Q^{T}(K ; \bar{Z})=v^{T}(K ; \bar{Z}) \bar{Z}+r K
$$

where $\bar{Z}$ and $K$ represent aggregate (industry) inputs of licenses and capital respectively. Equation (10) implicitly defines the equilibrium level of investment under transferability, which is denoted $K^{T}(\bar{Z})$.

Consider the left hand side of Equation (10) first. Since an increase in $K$ shifts supply out, moving the equilibrium down the demand curve, $P^{T}(K ; \bar{Z}) Q^{T}(K ; \bar{Z})$ is increasing in $K$ if demand elasticity exceeds unity, constant if demand elasticity equals unity, and decreasing in $K$ if demand elasticity is less than unity. As for the right hand side of Equation (10), the second term, $r K$, is clearly increasing in $K$, but the first term, $v^{T}(K ; \bar{Z}) \bar{Z}$, may be increasing or decreasing in $K$ : as noted in Lemma 2, it is likely to be increasing in $K$ if demand elasticity is high and decreasing in $K$ if demand elasticity is low. If both inputs are essential, both the 
$P^{T}(K ; \bar{Z}) Q^{T}(K ; \bar{Z})$ line and the $v^{T}(K ; \bar{Z}) \bar{Z}+r K$ line must emanate from the origin when graphed against $K^{5}$ In addition, for stability, $v^{T}(K ; \bar{Z}) \bar{Z}+r K$ must intersect $P^{T}(K ; \bar{Z}) Q^{T}(K ; \bar{Z})$ from below. ${ }^{6}$ Figures 1,2 , and 3 illustrate these lines in the fixed coefficients production setting discussed in Section $\mathrm{V}$ below.

Proposition 1: An increase in the input quota can raise or lower entry.

Proof: An increase in $\bar{Z}$ shifts the $P^{T}(K ; \bar{Z}) Q^{T}(K ; \bar{Z})$ line-graphed against $K$ upward if demand elasticity exceeds unity; downward if demand elasticity is less than unity; and has no effect if demand elasticity equals unity. ${ }^{7}$ The $v^{T}(K ; \bar{Z}) \bar{Z}+r K$ line may shift up or down in response to an increase in $\bar{Z}$ since $v_{\bar{Z}}^{T}(K ; \bar{Z})<0$ from Lemma 2 . Hence raising $\bar{Z}$ can raise or lower entry in general.

Proposition 1 implies that liberalizing the quantity control on intermediate inputs can shrink an industry under certain circumstances. ${ }^{8}$ For example, if demand elasticity is high, both the $P^{T}(K ; \bar{Z}) Q^{T}(K ; \bar{Z})$ and $v^{T}(K ; \bar{Z}) \bar{Z}+r K$ lines are upward sloping, and an increase in $\bar{Z}$ would shift the $P^{T}(K ; \bar{Z}) Q^{T}(K ; \bar{Z})$ line up and the $v^{T}(K ; \bar{Z}) \bar{Z}+r K$ line down if the inputs are easily substitutable (since the increase in $\bar{Z}$ would lead to a large fall in $v^{T}$ ); hence an increase in the input quota would lead to an increase in investment in this case. Section V contains two examples that cast more light on this issue.

${ }^{5}$ If both inputs are essential, then when $K$ is zero, output $\left(Q^{T}\right)$ is zero and there is no license demand so the license price $\left(v^{T}\right)$ is also zero. Hence, $P^{T}(K ; \bar{Z}) Q^{T}(K ; \bar{Z})=0$ and $v^{T}(K ; \bar{Z}) \bar{Z}+r K=0$ when $K=0$ in this case.

${ }^{6}$ For stability, $K$ should increase (decrease) when industry profits are positive (negative).

${ }^{7}$ An increase in $\bar{Z}$ increases output (from Lemma 1 ) and lowers the product price. For a given $K$, if demand is elastic, revenue rises along with $\bar{Z}$ so the $P^{T}(K ; \bar{Z}) Q^{T}(K ; \bar{Z})$ line shifts up.

${ }^{8}$ It is easy to show that this result obtains even in the absence of uncertainty; it does not hinge on license transferability. It may also be possible to obtain this result in a general equilibrium framework where relaxing the quota generates negative income effects for quota holders due to lower license prices; in general, however, in such models, these income losses tend to be outweighed by the direct gains from relaxing the quota. 


\section{NONTRANSFerable LiCENSES}

Now consider the case of nontransferable licenses. In this case, firms have to purchase their licenses before knowing $\beta$ and they are unable to re-optimize (i.e., trade their licenses) after $\beta$ is realized. Specifically, the timing is as follows:

1) In Period 1, the level of investment (or the number of firms), $K$, and the demand for licenses, $Z$, are determined given $\bar{Z}$. Hence, the market for licenses clears in Period 1.

2) In Period $2, \beta$ is realized, i.e., each firm faces a (different) productivity shock. At that time, production takes place. Hence the market for the final good clears in Period 2.

\section{A. Period 2}

\section{Product market clearing}

Consider an individual firm's production function given by Equation (1). Given that $K=1$ for each firm that entered the industry in Period 1, and that the firms are ex ante identical, all firms will have obtained the same number of licenses in Period 1 :

$$
z^{N T}(K ; \bar{Z})=\frac{\bar{Z}}{K}
$$

Hence, in Period 2, all firms will have the same amount of capital and the same number of licenses. However, they will not produce the same amount of output: the output of each firm will depend on its realization of $\beta$. Industry output in Period 2 is thus:

$$
Q^{N T}(K ; \bar{Z})=K \int_{\beta} \beta f(\bar{Z} / K) h(\beta) d \beta=K E(\beta) f(\bar{Z} / K)
$$

Lemma $3: Q_{K}^{N T}(K ; \bar{Z})>0$ and $Q_{\bar{Z}}^{N T}(K ; \bar{Z})>0$.

Proof: $Q_{K}^{N T}(K ; \bar{Z})=E(\beta)\left[f(\bar{Z} / K)-(\bar{Z} / K) f_{z}(\bar{Z} / K)\right]>0$ since $f(z) / z>f_{z}(z)$.

$Q_{\bar{Z}}^{N T}(K ; \bar{Z})>0$ follows from Equation (12).

Setting total supply equal to total demand for the final good:

$$
Q^{N T}(K ; \widetilde{Z})=D(P)
$$

yields the equilibrium product price as a function of $K$ : 


$$
P^{N T}(K ; \bar{Z})=D^{-1}\left(Q^{N T}(K ; \bar{Z})\right)
$$

As before, $P_{K}^{N T}(K ; \bar{Z})<0$ and $P_{\bar{Z}}^{N T}(K ; \bar{Z})<0$.

\section{B. Period 1}

In Period 1, the level of investment (or the number of firms), $K$, and the demand for licenses, $Z$, are determined, given $\bar{Z}$. Only the distribution of $\beta$ is known at this stage; the realization of $\beta$ for each firm will be known in Period 2.

Each firm is willing to pay the expected value of marginal product of a license. And, as mentioned earlier, since firms are ex ante identical, each firm will purchase $\bar{Z} / K$ licenses. Hence, the license price under nontransferability is:

$$
v^{N T}(K ; \bar{Z})=\int_{\beta} P^{N T}(K ; \bar{Z}) \beta f_{z}(\bar{Z} / K) h(\beta) d \beta=D^{-1}\left(Q^{N T}(K ; \bar{Z})\right) E(\beta) f_{z}(\bar{Z} / K)
$$

Lemma $4: v_{\bar{Z}}^{N T}(K ; \bar{Z})<0$ but the sign of $v_{K}^{N T}(K ; \bar{Z})$ is ambiguous.

Proof: The proof is the same as in Lemma 2.

Note from Equations (12) and (15) that if the uncertainty takes the form of a mean-preserving spread in firm output, then the outcome with nontransferable licenses is the same as it would have been in the absence of uncertainty. In other words, the introduction of uncertainty in the form of a mean-preserving spread in output will have no effect on the level of investment if the restricted input is nontransferable, but may lead to higher or lower investment if the restricted input is transferable.

In Period 1, entry and exit of firms will determine the total level of investment (or industry size), $K$. As before, the zero-profit condition is:

$$
P^{N T}(K ; \bar{Z}) Q^{N T}(K ; \bar{Z})=v^{N T}(K ; \bar{Z}) \bar{Z}+r K
$$

First consider the left hand side of Equation (16). Note that the position of the $P^{N T}(K ; \bar{Z}) Q^{N T}(K ; \bar{Z})$ line may be different than the $P^{T}(K ; \bar{Z}) Q^{T}(K ; \bar{Z})$ line considered previously. Recall that under transferability, firms with a low realization of $\beta$ can sell their licenses to those with a high realization in Period 2. Such license trades raise output (since the high- $\beta$ firms will produce more) so that for any $K$, output under transferability is greater than output under nontransferability. If the value of output- $P(K ; \bar{Z}) Q(K ; \bar{Z})$-is decreasing in $K$, then the $P(K ; \bar{Z}) Q(K ; \bar{Z})$ line will be lower under transferability than under nontransferability. If the value of output is increasing in $K$, then the $P(K ; \bar{Z}) Q(K ; \bar{Z})$ line will be higher under transferability than under nontransferability. And if the value of output 
is independent of $K$ then the $P(K ; \bar{Z}) Q(K ; \bar{Z})$ line will be the same under transferability and nontransferability.

Now consider the right hand side of Equation (16). The second term, $r K$, is increasing in $K$. But the first term, $v^{N T}(K ; \bar{Z}) \bar{Z}$ may be increasing or decreasing in $K$, as noted above. How does $v(K ; \bar{Z})$ differ under transferability and nontransferability? This comparison is likely to be complex. Krishna and Tan (1998) show that when the quota is very restrictive relative to $K$, i.e., when $K$ is large enough, then $v$ is higher under transferability than under nontransferability, and when $\bar{Z} / K$ is very large then $v$ is lower under transferability than under nontransferability. Thus a monotonic relation between the transferable and nontransferable license price is unlikely in general.

Finally, note that Proposition 1 holds true for the nontransferable case as well.

The following section presents illustrative examples using specific functional forms, namely, a constant elasticity of demand function and: (1) Cobb Douglas production; and (2) fixed coefficients production.

\section{EXAMPLES}

\section{A. Cobb Douglas Production Function}

Suppose the final good is produced using a Cobb Douglas production function: $F(K, Z)=K^{\alpha} Z^{1-\alpha}$, where $0<\alpha<1$. The Cobb Douglas technology, which is commonly assumed in agricultural applications, implies that all inputs are essential for production, i.e., both capital and licenses must be used in strictly positive amounts to obtain a positive output. The intensive form for the firm's production function can be written as:

$$
q=\beta f(z)=\beta z^{1-\alpha}
$$

Assume that $\beta$ is uniformly distributed between 0 and 2 , so $h(\beta)=1 / 2$ and $E(\beta)=1$.

Assume that the demand for the final product is isoelastic, with elasticity $\varepsilon$ :

$$
D=P^{-\delta}
$$

Consider first the case of transferable licenses. Using Equations (4), (6), and (8), it can be shown that:

$$
P^{T}(K ; \bar{Z}) Q^{T}(K ; \bar{Z})=\left(2 \bar{Z}^{1-\alpha}\left(\frac{\alpha K}{1+\alpha}\right)^{\alpha}\right)^{\frac{\varepsilon-1}{\varepsilon}}
$$

and: 


$$
v^{T}(K ; \bar{Z}) \bar{Z}+r K=(1-\alpha)\left(2 \bar{Z}^{1-\alpha}\left(\frac{\alpha K}{1+\alpha}\right)^{\alpha}\right)^{\frac{\varepsilon-1}{\varepsilon}}+r K
$$

Note from Equation (19) that $P^{T}(K ; \bar{Z}) Q^{T}(K ; \bar{Z})$ is increasing in $K$ if $\varepsilon>1$; decreasing in $K$ if $\varepsilon<1$; and constant if $\varepsilon=1$. From Equation (20), if $\varepsilon \geq 1$ then $v^{T}(K ; \bar{Z}) \bar{Z}+r K$ is increasing in $K$, but if $\varepsilon<1$ then $v^{T}(K ; \bar{Z}) \bar{Z}+r K$ may be increasing or decreasing in $K$.

Equating (19) and (20) yields the total level of investment under transferability:

$$
K^{T}(\bar{Z})=\left(2 \bar{Z}^{1-\alpha}\left(\frac{\alpha}{r}\right)^{\frac{\varepsilon}{\varepsilon-1}}\left(\frac{\alpha}{1+\alpha}\right)^{\alpha}\right)^{\frac{\varepsilon-1}{\varepsilon(1-\alpha)+\alpha}}
$$

Thus, $K^{T}$ is increasing in $\bar{Z}$ if $\varepsilon>1$; independent of $\bar{Z}$ (and equal to $\alpha / r$ ) if $\varepsilon=1$; and decreasing in $\bar{Z}$ if $\varepsilon<1$. From Equation (21), it follows that liberalizing the input restriction can actually result in a contraction in industry size if demand for the final good is very inelastic.

The equilibrium transferable license price is:

$$
v^{T}(\bar{Z})=(1-\alpha)\left(2 \bar{Z}^{\frac{-1}{\delta-1}}\left(\frac{\alpha}{r}\right)^{\alpha}\left(\frac{\alpha}{1+\alpha}\right)^{\alpha}\right)^{\frac{\varepsilon-1}{\varepsilon(1-\alpha)+\alpha}}
$$

The equilibrium final good price is:

$$
P^{T}(\bar{Z})=\left(\left(\frac{1}{2 \bar{Z}^{1-\alpha}}\right)\left(\frac{\alpha}{r}\right)^{-\alpha}\left(\frac{\alpha}{1+\alpha}\right)^{-\alpha}\right)^{\frac{1}{\varepsilon(1-\alpha)+\alpha}}
$$

Equations (22) and Equation (23) imply that the total effect of an increase in the input quota is to lower the license price and to increase output, thereby reducing the final product price. ${ }^{9}$

\footnotetext{
${ }^{9}$ The general intuition is that in all three cases, there is a direct effect through $\bar{Z}$ and an indirect effect through $K$, and the direct effect outweighs the indirect effect. For example, recall that $v_{\bar{Z}}^{T}(\bar{Z})=v_{\bar{Z}}^{T}(K ; \bar{Z})+v_{K}^{T}(K ; \bar{Z}) K_{\bar{Z}}^{T}(\bar{Z})$. Although $v_{\bar{Z}}^{T}(K ; \bar{Z})<0$ and $v_{K}^{T}(K ; \bar{Z}) K_{\bar{Z}}^{T}(\bar{Z})>0$, the first (direct) effect outweighs the second (indirect) effect.
} 
Although industry size may rise or fall with $\ddot{Z}$, the price of the final good is always negatively related to $\bar{Z}$ so output is always positively related to $\bar{Z}$. Hence, liberalizing the input restriction always leads to an increase in output and a reduction in the final good price.

Now consider the case of nontransferable licenses. Using Equations (12), (14), and (15), it can be shown that:

$$
P^{N T}(K ; \bar{Z}) Q^{N T}(K ; \bar{Z})=\left(K^{\alpha} \bar{Z}^{1-\alpha}\right)^{\frac{\varepsilon-1}{\varepsilon}}
$$

and:

$$
v^{N T}(K ; \bar{Z}) \bar{Z}+r K=(1-\alpha)\left(K^{\alpha} \bar{Z}^{1-\alpha}\right)^{\frac{\varepsilon-1}{\varepsilon}}+r K
$$

As in the transferable case, $P^{N T}(K ; \bar{Z}) Q^{N T}(K ; \bar{Z})$ is increasing in $K$ if $\varepsilon>1$; decreasing in $K$ if $\varepsilon<1$; and constant if $\varepsilon=1$. From Equation (25), if $\varepsilon \geq 1$ then $v^{N T}(K ; \bar{Z}) \bar{Z}+r K$ is increasing in $K$, but if $\varepsilon<1$ then $v^{N T}(K ; \bar{Z}) \bar{Z}+r K$ may be increasing or decreasing in $K$.

Equating Equations (24) and (25) yields the total level of investment under nontransferability:

$$
K^{N T}(\bar{Z})=\left(\bar{Z}^{1-\alpha}\left(\frac{\alpha}{r}\right)^{\frac{\varepsilon}{\varepsilon-1}}\right)^{\frac{\varepsilon-1}{\varepsilon(1-\alpha)+\alpha}}
$$

The equilibrium nontransferable license price is thus:

$$
v^{N T}(\bar{Z})=(1-\alpha)\left(\bar{Z}^{\frac{-1}{\varepsilon-1}}\left(\frac{\alpha}{r}\right)^{\alpha}\right)^{\frac{\varepsilon-1}{\varepsilon(1-\alpha)+\alpha}}
$$

The equilibrium final good price is:

$$
P^{N r}(\bar{Z})=\left(\left(\frac{1}{\bar{Z}^{1-\alpha}}\right)\left(\frac{\alpha}{r}\right)^{-\alpha}\right)^{\frac{1}{\varepsilon(1-\alpha)+\alpha}}
$$

To summarize: (i) the equilibrium license price and level of investment may be higher or lower under transferability compared with nontransferability, depending on how elastic the 
demand for the final product is-specifically, $K^{T}>K^{N T}$ and $v^{T}>v^{N T}$ if $\varepsilon>1 ; K^{T}<K^{N T}$ and $v^{T}<v^{N T}$ if $\varepsilon<1$; and $K^{T}=K^{N T}$ and $v^{T}=v^{N T}$ if $\varepsilon=1$; and (ii) the product price is always lower and output is always higher under transferability than under nontransferability. The first result follows from comparing Equations (21) and (26) and Equations (22) and (27):

$$
\frac{K^{T}}{K^{N T}}=\frac{v^{T}}{v^{N T}}=\left[2\left(\frac{\alpha}{1+\alpha}\right)^{\alpha}\right]^{\frac{\varepsilon-1}{\varepsilon(1-\alpha)+\alpha}}
$$

The second result follows from comparing Equations (23) and (28):

$$
\frac{P^{T}}{P^{N T}}=\left[2\left(\frac{\alpha}{1+\alpha}\right)^{\alpha}\right]^{\frac{-\alpha}{\varepsilon(1-\alpha)+\alpha}}
$$

Simulations show that $2[\alpha /(1+\alpha)]^{\alpha}>1$ for $0<\alpha<1 .{ }^{10}$

\section{B. Fixed Coefficients Production Function}

Suppose the final good is produced using a Leontief (fixed coefficients) production function: $F(K, Z)=\min (K, Z)$. To produce one unit of output, $K$ and $Z$ have to be combined in a specified ratio; there is no possibility of substitution between the inputs. This is a useful representation for production or export licenses.

The firm's production function can be written as:

$$
q=\beta f(z)=\beta \min (1, z)
$$

Note that $f_{z}(z)=1$ for $0 \leq z<1$ and 0 for $z \geq 1$. Hence the Leontief production function does not meet the Inada conditions. As before, assume that $\beta$ is uniformily distributed between 0 and 2 , and that the demand for the final product is isoelastic with elasticity $\varepsilon$.

Consider, for example, a quota on the number of fish that can be caught. Each firm has one unit of capital (a boat-trip with a fixed capacity, say) which it has to combine with $z$ licenses in order to be able to catch fish. Increasing the number of licenses beyond the fixed capacity will not increase the number of fish brought ashore; neither will increasing the capacity beyond that allowed by the number of licenses held increase the number of fish

${ }^{10}$ When plotted with $\alpha$ on the horizontal axis, the line representing $\alpha /(1+\alpha)$ lies above the line representing $(1 / 2)^{1 / \alpha}$ for $0<\alpha<1$. 
brought ashore. Output is measured in terms of the total weight of the catch. Each firm draws a random catch (due to luck, weather, etc.) which is not known until Period $2 ; \beta$ is a random variable that determines the weight of the catch. So a firm utilizes one boat-trip combined with $z$ licenses to "produce" a catch weighing $\beta$ pounds.

First consider the case of transferable licenses. It can be shown that:

$$
P^{T}(K ; \bar{Z}) Q^{T}(K ; \bar{Z})= \begin{cases}K^{\frac{\varepsilon-1}{\varepsilon}} & \text { if } K \leq \bar{Z} \\ \left(\bar{Z}\left(2-\frac{\bar{Z}}{K}\right)\right)^{\frac{\varepsilon-1}{\varepsilon}} & \text { if } K \geq \bar{Z}\end{cases}
$$

and:

$$
v^{T}(K ; \bar{Z}) \bar{Z}+r K= \begin{cases}r K & \text { if } K \leq \bar{Z} \\ 2 \bar{Z}^{\frac{\varepsilon-1}{\varepsilon}}\left(1-\frac{\bar{Z}}{K}\right)\left(2-\frac{\bar{Z}}{K}\right)^{-1 / s}+r K & \text { if } K \geq \bar{Z}\end{cases}
$$

(See Appendix II for the derivation.) As expected, the first line, $P^{T}(K ; \bar{Z}) Q^{T}(K ; \bar{Z})$, is non-decreasing in $K$ if $\varepsilon>1$; non-increasing in $K$ if $\varepsilon<1$; and constant (and equal to 1) if $\varepsilon=1$. The second line, $v^{T}(K ; \bar{Z}) \bar{Z}+r K$ is a continuous line that has a slope of $r$ for $K \leq \bar{Z}$; has a slope less than $r$ for $K>\bar{Z}$; and takes the value of $r \bar{Z}$ at $K=\bar{Z}$.

Equations (32) and (33) are illustrated in Figures 1, 2, and 3 for $\varepsilon>1, \varepsilon<1$, and $\varepsilon=1$ respectively. The equilibrium level of investment under transferability is given by the intersection of the two lines, $P^{T}(K ; \bar{Z}) Q^{T}(K ; \bar{Z})$ and $v^{T}(K ; \bar{Z}) \bar{Z}+r K$. If $P^{T}(K ; \bar{Z}) Q^{T}(K ; \bar{Z})<v^{T}(K ; \bar{Z}) \bar{Z}+r K$ at $K=\bar{Z}$, then profits are negative at $K=\bar{Z}$, so the equilibrium level of $K^{T}$ must occur below $\bar{Z}$. In this case-which occurs when $\bar{Z}>r^{-\varepsilon}$ - the equilibrium $K^{T}$ will be given by the intersection of $K^{(\varepsilon-1) / \varepsilon}$ and $r K$. So:

$$
K^{T}=r^{-\varepsilon}
$$

when $\bar{Z}>r^{-\varepsilon}$. This is depicted in Figures 1(a), 2(a), and 3(a). If $P^{T}(K ; \bar{Z}) Q^{T}(K ; \bar{Z})=v^{T^{T}}(K ; \bar{Z}) \bar{Z}+r K$ at $K=\bar{Z}$, then the equilibrium level of $K^{T}$ occurs at $\bar{Z}$. This case-which occurs when $\bar{Z}=r^{-E}$-is depicted in Figures $1(\mathrm{~b}), 2(\mathrm{~b})$, and 3(b). If $P^{T}(K ; \bar{Z}) Q^{T}(K ; \bar{Z})>v^{T}(K ; \bar{Z}) \bar{Z}+r K$ at $K=\bar{Z}$, then profits are positive at $K=\bar{Z}$, so the equilibrium level of $K^{T}$ must occur above $\bar{Z}$. In this case-which occurs when $\bar{Z}<r^{-\varepsilon}$-the 
equilibrium $K^{T}$ will be given by the intersection of $\bar{Z}(2-(\bar{Z} / K))^{(\varepsilon-1) / s}$ and $2 \bar{Z}^{(\varepsilon-1) / \varepsilon}(1-(\bar{Z} / K))(2-(\bar{Z} / K))^{-1 / \varepsilon}+r K$. So $K^{T}(\bar{Z})$ is defined implicitly by:

$$
\left(\bar{Z}\left(2-\frac{\bar{Z}}{K^{T}}\right)\right)^{-1 / \varepsilon}\left(\frac{\bar{Z}}{K^{T}}\right)^{2}=r
$$

when $\bar{Z}<r^{-\varepsilon}$. This is depicted in Figures 1(c), 2(c), and 3(c).

Note from Equations (34) and (35) that $K^{T}$ is independent of $\bar{Z}$ (and equal to $r^{-\delta}$ ) if the input quota is relatively large $\left(\bar{Z} \geq r^{-E}\right)$, and may increase or decrease with $\bar{Z}$ if the input quota is relatively small $\left(\bar{Z}<r^{-E}\right)$. Implicitly differentiating Equation (35), it can be shown that $K_{\bar{Z}}^{T}<0$ if $\varepsilon<\left[1-\left(\bar{Z} / K^{T}\right] /\left[2-\left(\bar{Z} / K^{T}\right)\right]\right.$. Since $\bar{Z} / K^{T}$ is bounded away from unity in this region, the right hand side of the inequality is bounded away from zero. ${ }^{11}$ This is in line with the argument following Proposition 1, which suggests that if demand elasticity is high then investment rises with $\bar{Z}$.

The equilibrium transferable license price, $v^{T}(\bar{Z})$ is:

$$
v^{T}(\bar{Z})= \begin{cases}0 & \text { if } \bar{Z} \geq r^{-\varepsilon} \\ 2 r\left(\frac{\bar{Z}}{K^{T}(\bar{Z})}\right)^{-2}\left(1-\frac{\bar{Z}}{K^{T}(\bar{Z})}\right) & \text { if } \bar{Z} \leq r^{-\varepsilon}\end{cases}
$$

where $K^{T}(\bar{Z})$ is given by Equation (35). Thus, the equilibrium license price is independent of $\bar{Z}$ (and equal to zero) if the input quota is relatively large $\left(\bar{Z} \geq r^{-\varepsilon}\right)$, and decreases with $\bar{Z}$ if the input quota is relatively small $\left(\bar{Z}<r^{-E}\right)$.

Now consider the case of nontransferable licenses. Then each firm will have $\bar{Z} / K$ licenses and all firms will produce in Period 2. If $K \leq \bar{Z}$, then total output is $K$ and the product price is $K^{-1 / \varepsilon}$. If $K \geq \bar{Z}$, then the total output is $\bar{Z}$ and the product price is $\bar{Z}^{-1 / \varepsilon}$. Hence:

${ }^{11}$ Consider an increase in $\bar{Z}$ with a proportional increase in $K^{T}$ so that $\bar{Z} / K^{T}$ is unchanged. Then the left hand side of Equation (35) will fall and the equality will no longer hold. Therefore for Equation (35) to hold, an increase in $\bar{Z}$ has to be accompanied by an increase in $\bar{Z} / K^{T}$. This means that $K^{T}$ must increase less than proportionately with $\bar{Z}$ or even decrease with $\bar{Z}$. 


$$
P^{N T}(K ; \bar{Z}) Q^{N T}(K ; \bar{Z})= \begin{cases}K^{\frac{\varepsilon-1}{s}} & \text { if } K \leq \bar{Z} \\ \bar{Z}^{\frac{\varepsilon-1}{s}} & \text { if } K \geq \bar{Z}\end{cases}
$$

As in the transferable case, $P^{N T}(K ; \bar{Z}) Q^{N T}(K ; \bar{Z})$ is non-decreasing in $K$ if $\varepsilon>1$; non-increasing in $K$ if $\varepsilon<1$; and constant (and equal to 1 ) if $\varepsilon=1$. In addition, the $P(K ; \bar{Z}) Q(K ; \bar{Z})$ line under nontransferability coincides with that under transferability when $K \leq \bar{Z}$. When $K>\bar{Z}$, the $P(K ; \bar{Z}) Q(K ; \bar{Z})$ line under nontransferability lies below that under transferability if $\varepsilon>1$ and above it if $\varepsilon<1$, as expected from the discussion in Section IV. If $\varepsilon=1$, then the $P(K ; \bar{Z}) Q(K ; \bar{Z})$ lines are horizontal and are identical under transferability and nontransferability.

In Period 1, if $K<\bar{Z}$, then the expected marginal value product of a license is zero, so $v^{N T}=0$. If $K>\bar{Z}$, then the expected marginal value product of a license is $\bar{Z}^{-1 / \varepsilon}$, so $v^{N T}=\bar{Z}^{-1 / \varepsilon}$. If $K=\bar{Z}$, one has to use the subgradient since the marginal product of $z$ is not continuously differentiable at $z=1$. Hence:

$$
v^{N T}(K ; \bar{Z}) \bar{Z}+r K= \begin{cases}r K & \text { if } K<\bar{Z} \\ {\left[r K, \bar{Z}^{\frac{\varepsilon-1}{\varepsilon}}+r K\right]} & \text { if } K=\bar{Z} \\ \bar{Z}^{\frac{\varepsilon-1}{\varepsilon}}+r K & \text { if } K>\bar{Z}\end{cases}
$$

The $v^{N T}(K ; \bar{Z}) \bar{Z}+r K$ line under nontransferability coincides with that under transferability when $K<\bar{Z}$; it jumps up by $\bar{Z}^{(\varepsilon-1) / \varepsilon}$ at $K=\bar{Z}$.

Equations (37) and (38) are also depicted in Figures 1, 2, and 3 for $\varepsilon>1, \varepsilon<1$, and $\varepsilon=1$ respectively. The equilibrium level of investment under nontransferability- $K^{N T}$-is at the intersection of (37) and (38). If $P^{N T}(K ; \bar{Z}) Q^{N T}(K ; \bar{Z}) \leq v^{N T}(K ; \bar{Z}) \bar{Z}+r K$ at $K=\bar{Z}$, then $K^{N T}=K^{T}$. This is depicted in Figures $1(\mathrm{a})-(\mathrm{b}), 2(\mathrm{a})-(\mathrm{b})$, and $3(\mathrm{a})$-(b). If $P^{N T}(K ; \bar{Z}) Q^{N T}(K ; \bar{Z})>v^{N T}(K ; \bar{Z}) \bar{Z}+r K$ at $K=\bar{Z}$, then $K^{N T}=\bar{Z}<K^{T}$. This is depicted in Figures 1(c), 2(c), and 3(c).

Intuitively, the expected value of the marginal product of $K$ is equal to $P^{N T}(K ; \bar{Z})=K^{-1 / s}$ if $K<\bar{Z}$, and is equal to zero if $K \geq \bar{Z}$. However, since the price of $K$ is $r, K$ will not be purchased beyond the point where its expected marginal product value is equal to its marginal cost, i.e., where $K^{-1 / \varepsilon}=r$ (or $K=r^{-\varepsilon}$ ). Hence if $\bar{Z}>r^{-\varepsilon}$ then the level of investment will be equal to $r^{-\varepsilon}$, but if $\bar{Z} \leq r^{-\varepsilon}$ then the level of investment will be equal to Z Thus: 


$$
K^{N T}(\bar{Z})= \begin{cases}r^{-\varepsilon} & \text { if } \bar{Z} \geq r^{-\varepsilon} \\ \bar{Z} & \text { if } \bar{Z} \leq r^{-\varepsilon}\end{cases}
$$

Note that $K^{N T}$ is independent of $\bar{Z}$ (and equal to $r^{-5}$ ) if the input quota is relatively large ( $\bar{Z} \geq r^{-\varepsilon}$ ), and increases with $\bar{Z}$ if the input quota is relatively small $\left(\bar{Z}<r^{-\varepsilon}\right)$. In other words, industry size increases as the quantity control is relaxed, up to a point $r^{-\varepsilon}$; beyond this point, further increases in $\bar{Z}$ have no effect on industry size. In comparison with the transferable case, industry size is weakly smaller under nontransferability than under transferability for every level of $\bar{Z}$.

As noted above, the equilibrium license price is:

$$
v^{N T}(\bar{Z})= \begin{cases}0 & \text { if } \bar{Z}>r^{-\varepsilon} \\ {\left[0, \bar{Z}^{-1 / \varepsilon}\right]} & \text { if } \bar{Z}=r^{-\varepsilon} \\ \bar{Z}^{-1 / \varepsilon} & \text { if } \bar{Z}<r^{-\hat{\varepsilon}}\end{cases}
$$

Thus, the equilibrium license price is independent of $\bar{Z}$ (and equal to zero) if the input quota is relatively large $\left(\bar{Z}>r^{-\varepsilon}\right)$, and decreases with $\bar{Z}$ if the input quota is relatively small $\left(\bar{Z}<r^{-\varepsilon}\right)$.

To summarize: (i) the equilibrium level of investment is weakly smaller under nontransferability than under transferability for every level of $\bar{Z}$; (ii) output is weakly lower (and consequently price is weakly higher) under nontransferability than under transferability; and (iii) the equilibrium nontransferable license price is the same as the equilibrium transferable license price $\left(v^{N T}=v^{T}=0\right.$ ) when the input quota is not binding (i.e., when $\bar{Z} \geq r^{-\varepsilon}$ ), but may be higher or lower than the equilibrium transferable license price when the input quota is binding (i.e., when $\bar{Z}<r^{-\varepsilon}$ ). The first result follows from Proposition 2 and Equation (39). When the input quota, $\bar{Z}$, is not binding (i.e., when $\bar{Z} \geq r^{-\varepsilon}$ ), then investment and output are the same (and equal to $r^{-\delta}$ ) under both regimes. When the input quota is binding (i.e., when $\bar{Z}<r^{-\varepsilon}$ ), under nontransferability, all firms will produce in Period 2, so output is $\bar{Z}$; but under transferability, only firms with a high productivity shock buy the licenses and produce whilst those with a low productivity shock do not produce in Period 2, so output is greater than $\bar{Z}$ and the price of the final good is lower than it would be under nontransferability. The equilibrium nontransferable license price is the same as the equilibrium transferable license price $\left(v^{N T}=v^{T}=0\right)$ when the quantity constraint is not binding (i.e., when $\bar{Z} \geq r^{-\varepsilon}$ ). When the quantity constraint is binding (i.e., when $\bar{Z}<r^{-\varepsilon}$ ), then $v^{N T}=\bar{Z}^{-1 / \varepsilon}$, which is smaller than $v^{T}$ (which is given by Equation (36)) if the equilibrium level of investment under transferability, $K^{T}$, is very large relative to the license supply, $\bar{Z}$; this, in turn, is likely to be the case if $\varepsilon$ is high (for a given $r$ ). 
The results can be understood intuitively as follows. When the license supply is small, output is necessarily small so the price of the final good is very high. As a result, the expected value of the marginal product of investment is very high. Under transferability, firms are willing to invest beyond $\bar{Z}$ since they know that they can buy a license and produce if they have a high enough realization of $\beta$. Under nontransferability, this will not happen. Hence investment/entry will be higher under transferability than under nontransferability. When the license supply is large, the final good price will be too low to cover costs if firms enter up to $\bar{Z}$. Hence, there will be fewer firms than licenses and ex post, no firm will be in want of a license. As a result, the license price will be zero and investment and output will be the same in both the transferable and nontransferable case.

\section{Conclusion}

Quantity controls on production inputs occur quite frequently in practice. These controls may be implemented in various ways. This paper analyzes the implications for a competitive industry of input rationing that is effected through the sale of licenses. Two cases are considered: the case of transferable licenses (i.e., where resale is allowed) and the case of nontransferable licenses (i.e., where resale is prohibited). Using partial equilibrium analysis and a two-input model of production with one restricted and one unrestricted input, it is shown that the implications for the license price and the level of investment in the industry are quite different in the two cases.

In general, there is no clearcut comparison between the level of investment, the license price, output, and the final product price under transferability and those under nontransferability. Key factors in the comparison include the elasticity of demand for the final good, the degree of substitutability between the restricted and unrestricted inputs, and the restrictiveness of the quota. With a Cobb Douglas production function, the equilibrium license price and level of investment under transferability are higher than under nontransferability if demand elasticity is high, and lower than under nontransferability if demand elasticity is low. However, output is always higher under transferability and consequently, the product price is always lower than under nontransferability. In the example of a fixed coefficients production function, where there is no substitution between the two inputs, investment/entry is higher, output is higher, and consequently, the final good price is lower under transferability than under nontransferability when the quota is binding (i.e., when the license supply is small); however, the license price may be higher or lower under transferability than under nontransferability. When the license supply is relatively large, the license price is zero and investment/entry, output, and the final good price are the same under transferability and nontransferability.

Finally, although it is often assumed that liberalizing the input restriction would increase investment in the affected industry, it is shown here that under certain conditionsnotably, if the demand for the final good is very inelastic and/or the inputs are very close substitutes-liberalizing the input restriction may actually shrink the industry rather than boost its growth. 
Proof of Lemma 1: $Q_{K}^{T}(K ; \bar{Z})>0$

From Equation (6):

$$
Q^{T}(K ; \bar{Z})=\int_{\beta} K \beta f(z(\cdot)) h(\beta) d \beta
$$

Differentiating with respect to $K$ :

$$
Q_{K}^{T}(K ; \bar{Z})=\int_{\beta}\left[\beta f(z(\cdot))+K \beta f_{z}(z(\cdot)) z_{K}(\cdot)\right] h(\beta) d \beta
$$

From Equation (2):

$$
\beta f_{z}(z)=\frac{v}{P}
$$

Substituting (43) in (42):

$$
Q_{K}^{T}(K ; \bar{Z})=\int_{\beta} f(z(\cdot)) \beta h(\beta) d \beta+\frac{v}{P} \int_{\beta} K z_{K}(\cdot) h(\beta) d \beta
$$

From Equation (4):

$$
\int_{\beta} K z(\cdot) h(\beta) d \beta=\bar{Z}
$$

Differentiating (45) with respect to $K$ :

$$
\begin{aligned}
& \int_{\beta} z(\cdot) h(\beta) d \beta+\int_{\beta} K z_{K}(\cdot) h(\beta) d \beta=0 \\
& \Rightarrow \int_{\beta} K z_{K}(\cdot) h(\beta) d \beta=-\int_{\beta} z(\cdot) h(\beta) d \beta
\end{aligned}
$$

Substituting (46) in (44):

$$
\begin{aligned}
Q_{K}^{T}(K ; \bar{Z}) & =\int_{\beta} f(z(\cdot)) \beta h(\beta) d \beta-\frac{v}{P} \int_{\beta} z(\cdot) h(\beta) d \beta \\
& =\int_{\beta} f(z(\cdot)) \beta h(\beta) d \beta-\int_{\beta} \beta f_{z}(z(\cdot)) z(\cdot) h(\beta) d \beta \\
& =\int_{\beta}\left[f(z(\cdot))-f_{z}(z(\cdot)) z(\cdot)\right] \beta h(\beta) d \beta \\
& >0
\end{aligned}
$$

since, by concavity, the average product of $z$ is greater than the marginal product of $z$, i.e.: 


$$
\frac{f(z(\cdot))}{z(\cdot)}>f_{z}(z(\cdot)) \Rightarrow f(z(\cdot))-f_{z}(z(\cdot)) z(\cdot)>0
$$

Proof of Lemma 1: $Q_{\bar{Z}}^{T}(K ; \bar{Z})>0$

From Equation (6):

$$
Q_{\bar{Z}}^{T}(K ; \bar{Z})=\int_{\beta} K \beta f(z(\cdot)) h(\beta) d \beta
$$

Differentiating with respect to $\bar{Z}$ :

$$
Q_{\bar{Z}}^{T}(K ; \bar{Z})=\int_{\beta} K \beta f_{z}(z(\cdot)) z_{\bar{Z}}(\cdot) h(\beta) d \beta
$$

From Equation (2):

$$
\beta f_{z}(z)=\frac{v}{P}
$$

Substituting (51) in (50):

$$
Q_{\bar{Z}}^{T}(K ; \bar{Z})=\frac{v}{P} \int_{\beta} K z_{\bar{Z}}(\cdot) h(\beta) d \beta
$$

From Equation (4):

$$
\int_{\beta} K z(\cdot) h(\beta) d \beta=\bar{Z}
$$

Differentiating (53) with respect to $\bar{Z}$ :

$$
\int_{\beta} K z_{\bar{Z}}(\cdot) h(\beta) d \beta=1
$$

Substituting (54) in (52):

$$
Q_{\bar{Z}}^{T}(K ; \bar{Z})=\frac{v}{P}>0
$$


Proof of Lemma 2: Sign of $v_{K}^{T}(K ; \bar{Z})$ is ambiguous

From Equation (9):

$$
v^{T}(K ; \bar{Z})=D^{-1}\left(Q^{T}(K ; \bar{Z})\right) \cdot g\left(\frac{\bar{Z}}{K}\right)
$$

Differentiating with respect to $K$ :

$$
v_{K}^{T}(K ; \bar{Z})=D^{-1^{\prime}}(Q) Q_{K}^{T}(K ; \bar{Z}) g\left(\frac{\bar{Z}}{K}\right)-D^{-1}(Q) g^{\prime}\left(\frac{\bar{Z}}{K}\right)\left(\frac{\bar{Z}}{K^{2}}\right)
$$

Define the following elasticities:

$$
\begin{aligned}
& \eta_{P}=-\frac{D^{-1^{\prime}}(Q) Q}{D^{-1}(Q)} \\
& \eta_{K}=\frac{Q_{K}^{T^{\prime}}(K ; \bar{Z}) K}{Q} \\
& \eta_{g}=-\frac{g^{\prime}(\bar{Z} / K)(\bar{Z} / K)}{g(\bar{Z} / K)}
\end{aligned}
$$

where $\eta_{P}, \eta_{K}$, and $\eta_{g}$ are positive numbers. $\eta_{P}$ is the reciprocal of the price elasticity of demand for the final product: the higher the price elasticity of demand, the lower is $\eta_{P} . \eta_{K}$ is the partial elasticity of supply with respect to $K$ for given $\bar{Z} . \eta_{g}$ is elasticity of the expectation of the inverse of the marginal product of $z$ with respect to the relative scarcity of licenses, $\bar{Z} / K$. Both $\eta_{g}$ and $\eta_{K}$ are related to the degree of substitutability between $Z$ and $K$ : the greater the substitutability between $Z$ and $K$, the smaller is $\eta_{g}$ (as $f_{z}$ is elastic so that $f_{z}^{-1}$ is inelastic) and the larger is $\eta_{K}$ (as output is very responsive to changes in $K$ ).

Multiplying and dividing the first term of Equation (57) by $D^{-1}, Q$, and $K$, and the second term of Equation (57) by $g$ :

$$
\begin{aligned}
v_{K}^{T}(K ; \bar{Z}) & =\left(\frac{D^{-1^{\prime}}(Q) Q}{D^{-1}(Q)}\right)\left(\frac{Q_{K}^{T}(K ; \bar{Z}) K}{Q}\right)\left(\frac{D^{-1}(Q) g(\bar{Z} / K)}{K}\right) \\
& -\left(\frac{D^{-1}(Q) g(\bar{Z} / K)}{K}\right)\left(\frac{g^{\prime}(\bar{Z} / K)(\bar{Z} / K)}{g(\bar{Z} / K)}\right) \\
& =\left(-\eta_{p} \eta_{Q}+\eta_{g}\right)\left(\frac{D^{-1}(Q) g(\bar{Z} / K)}{K}\right)
\end{aligned}
$$


The second bracketed term in Equation $(59), D^{-1}(\cdot) g(\cdot) / K$, is positive so the sign of $v_{K}(K ; \bar{Z})$ hinges on the first bracketed term, $\left(-\eta_{P} \eta_{Q}+\eta_{g}\right)$. If the price elasticity of demand is high, then $\eta_{P}$ is low and $\left(-\eta_{P} \eta_{Q}+\eta_{g}\right)$ is positive; if the price elasticity of demand is low, then $\eta_{P}$ is high and $\left(-\eta_{P} \eta_{Q}+\eta_{g}\right)$ is negative.

Proof of Lemma 2: $v_{\bar{Z}}^{T}(K ; \bar{Z})<0$

From Equation (9):

$$
v^{T}(K ; \bar{Z})=D^{-1}\left(Q^{T}(K ; \bar{Z})\right) \cdot g\left(\frac{\bar{Z}}{K}\right)
$$

Differentiating with respect to $\bar{Z}$ :

$$
v_{\bar{Z}}^{T}(K ; \bar{Z})=D^{-1^{\prime}}(Q) Q_{\bar{Z}}^{T}(K ; \bar{Z}) g\left(\frac{\bar{Z}}{K}\right)+D^{-1}(Q) g^{\prime}\left(\frac{\bar{Z}}{K}\right)\left(\frac{1}{K}\right)
$$

Define the following elasticities:

$$
\begin{aligned}
& \eta_{P}=-\frac{D^{-1^{\prime}}(Q) Q}{D^{-1}(Q)} \\
& \eta_{\bar{Z}}=\frac{Q_{\bar{Z}}^{T}(K ; \bar{Z}) \bar{Z}}{Q} \\
& \eta_{g}=-\frac{g^{\prime}(\bar{Z} / K)(\bar{Z} / K)}{g(\bar{Z} / K)}
\end{aligned}
$$

where $\eta_{P}, \eta_{\bar{Z}}$, and $\eta_{g}$ are positive numbers. $\eta_{P}$ and $\eta_{g}$ are defined as before. $\eta_{\bar{Z}}$ is the partial elasticity of supply with respect to $\bar{Z}$ for given $K$.

Multiplying and dividing the first term of Equation (61) by $D^{-1}, Q$, and $\bar{Z}$, and the second term of Equation (61) by $g$ : 


$$
\begin{aligned}
v_{\bar{Z}}^{T}(K ; \bar{Z}) & =\left(\frac{D^{-1^{\prime}}(Q) Q}{D^{-1}(Q)}\right)\left(\frac{Q_{Z}^{T}(K ; \bar{Z}) \bar{Z}}{Q}\right)\left(\frac{D^{-1}(Q) g(\bar{Z} / K)}{\bar{Z}}\right) \\
& +\left(\frac{D^{-1}(Q) g(\bar{Z} / K)}{\bar{Z}}\right)\left(\frac{g^{\prime}(\bar{Z} / K)(\bar{Z} / K)}{g(\bar{Z} / K)}\right) \\
& =\left(-\eta_{P} \eta_{\bar{Z}}-\eta_{g}\right)\left(\frac{D^{-1}(Q) g(\bar{Z} / K)}{\bar{Z}}\right)
\end{aligned}
$$

The first bracketed term in Equation (63), $-\eta_{p} \eta_{\bar{z}}-\eta_{g}$, is negative and the second bracketed term, $D^{-1}(\cdot) g(\cdot) / \bar{Z}$, is positive so $v_{\bar{Z}}(K ; \bar{Z})<0$. 


\section{Derivation of Equations (32) and (33)}

Since there is no substitution between capital and licenses, not every firm will find it profitable to buy a license and produce upon realizing its $\beta$ in Period 2 . A firm in Period 2 will demand a license only if the value of its marginal product, $\beta P$ (where $\beta$ is known) is greater than or equal to its cost, $v$. (The cost of capital is already sunk in Period 2.) Hence, only those firms with a "good" realization of $\beta$ will produce, where a "good" realization is defined to be $\beta \geq v / P$. Firms with a "bad" realization of $\beta$, i.e., those with $\beta<v / P$, will not find it worthwhile to produce.

The total demand for licenses is thus $K[1-v /(2 P)]$. Equating this with the total supply of licenses yields: $v^{T}(P, K ; \bar{Z})=2 P(1-\bar{Z} / K)$ if $K \geq \bar{Z}$ and 0 if $K<\bar{Z}$ (since the license price cannot be negative).

Total industry supply of the final $\operatorname{good}$ is $K \int_{\max [0, v / P]}^{2} \beta h(\beta) d \beta$, or:

$$
Q^{T}(K ; \bar{Z})= \begin{cases}K & \text { if } K \leq \bar{Z} \\ \bar{Z}\left(2-\frac{\bar{Z}}{K}\right) & \text { if } K \geq \bar{Z}\end{cases}
$$

Note that total supply can exceed $K$ since the licenses are used only by the most efficient firms.

Equating total supply with total demand yields:

$$
P^{T}(K ; \bar{Z})= \begin{cases}K^{-1 / \varepsilon} & \text { if } K \leq \bar{Z} \\ \left(\bar{Z}\left(2-\frac{\bar{Z}}{K}\right)\right)^{-1 / \varepsilon} & \text { if } K \geq \bar{Z}\end{cases}
$$

Using (65), the equilibrium license price may be written as:

$$
v^{T}(K ; \bar{Z})= \begin{cases}0 & \text { if } K \leq \bar{Z} \\ 2\left(1-\frac{\bar{Z}}{K}\right)\left(\bar{Z}\left(2-\frac{\bar{Z}}{K}\right)\right)^{-1 / \varepsilon} & \text { if } K \geq \bar{Z}\end{cases}
$$

In Period 1, the equilibrium level of investment, $K$, is determined by the zero profit condition. Using Equations (64) and (65), it can be shown that: 


$$
P^{T}(K ; \bar{Z}) Q^{T}(K ; \bar{Z})= \begin{cases}K^{\frac{\varepsilon-1}{\varepsilon}} & \text { if } K \leq \bar{Z} \\ \left(\bar{Z}\left(2-\frac{\bar{Z}}{K}\right)\right)^{\frac{\varepsilon-1}{\varepsilon}} & \text { if } K \geq \bar{Z}\end{cases}
$$

Using Equation (66), it can be shown that:

$$
v^{T}(K ; \bar{Z}) \bar{Z}+r K= \begin{cases}r K & \text { if } K \leq \bar{Z} \\ 2 \bar{Z}^{\frac{\varepsilon-1}{\varepsilon}}\left(1-\frac{\bar{Z}}{K}\right)\left(2-\frac{\bar{Z}}{K}\right)^{-1 / \varepsilon}+r K & \text { if } K \geq \bar{Z}\end{cases}
$$


Figure 1. Fixed Coefficients Production, $\varepsilon>1$

(a) $\bar{Z}>r^{-\varepsilon}$

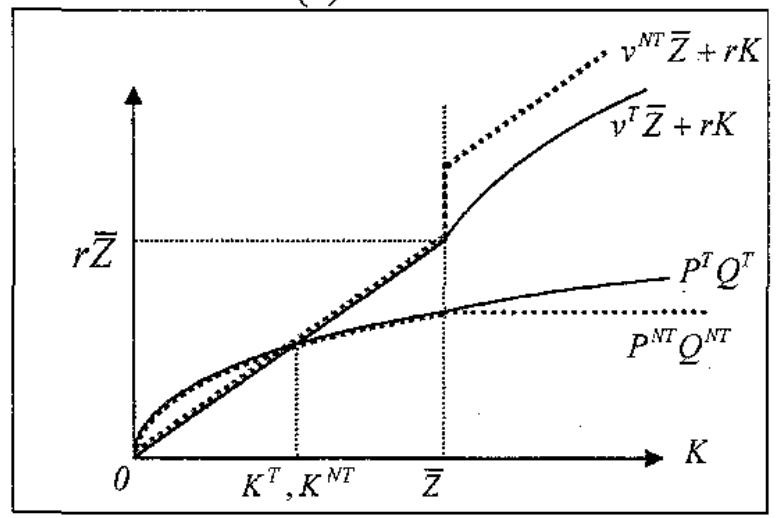

(b) $\bar{Z}=r^{-\varepsilon}$

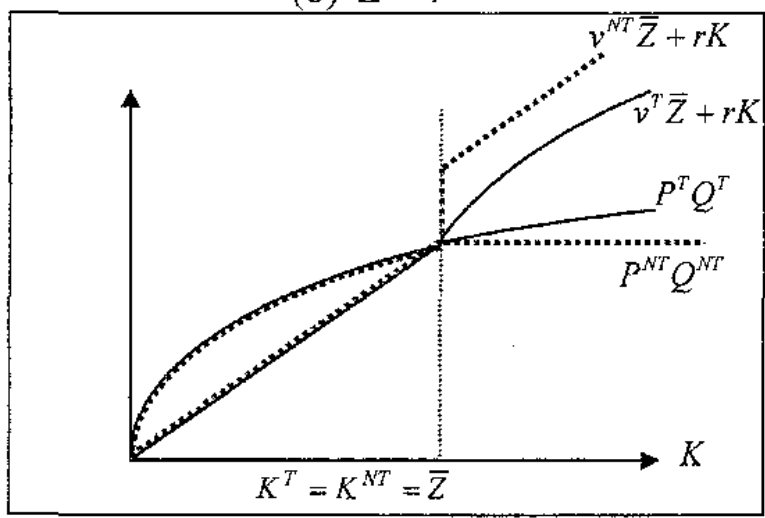

(c) $\bar{Z}<r^{-\varepsilon}$

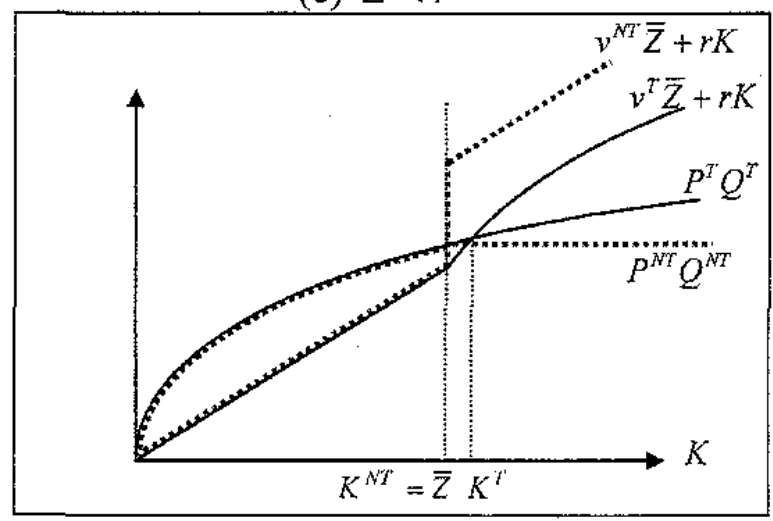


Figure 2. Fixed Coefficients Production, $\varepsilon<1$

(a) $\bar{Z}>r^{-\varepsilon}$

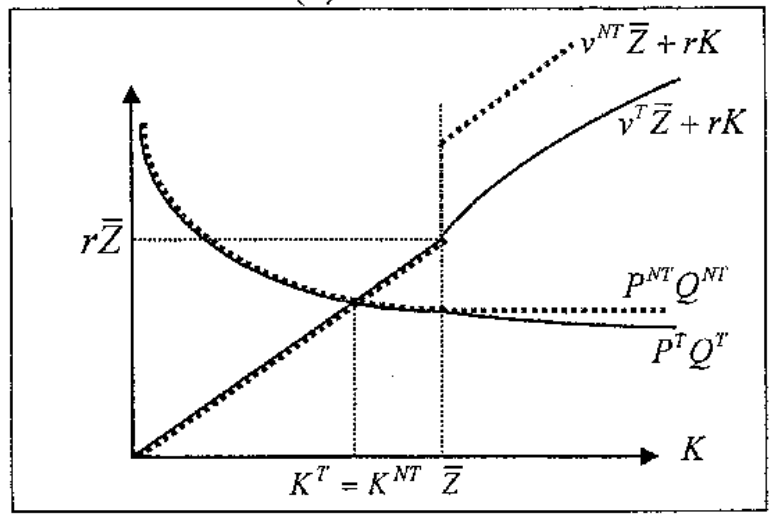

(b) $\bar{Z}=r^{-\varepsilon}$

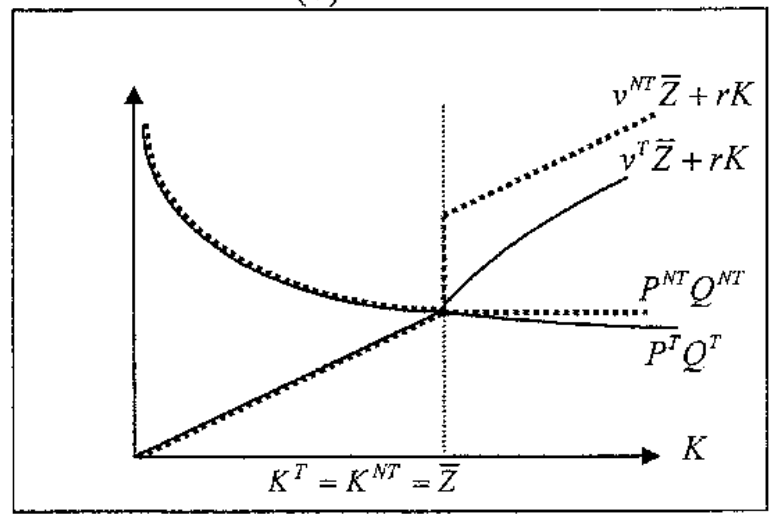

(c) $\bar{Z}<r^{-\varepsilon}$

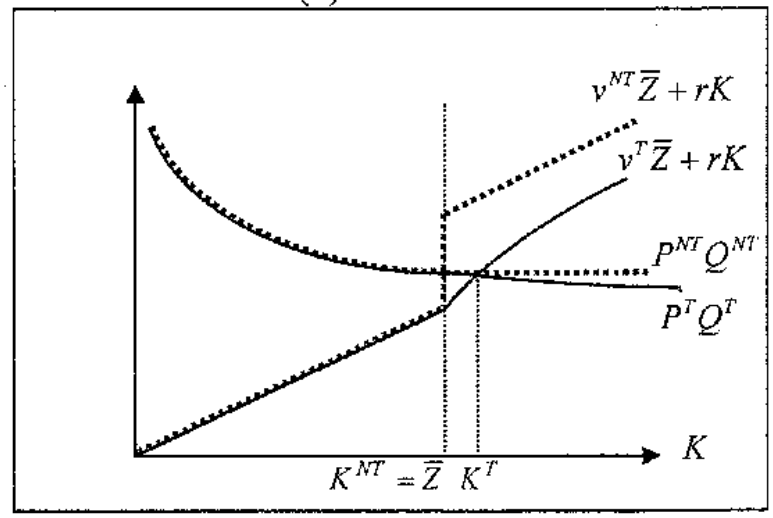


Figure 3. Fixed Coefficients Production, $\varepsilon=1$

(a) $\bar{Z}>r^{-\varepsilon}$

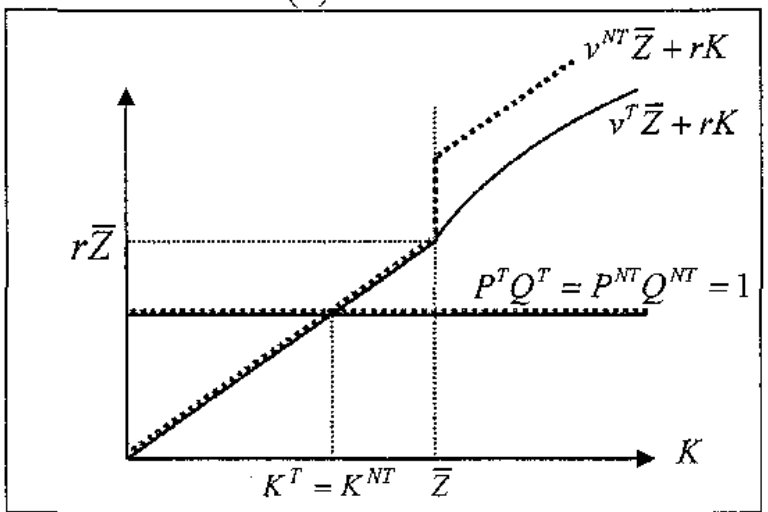

(b) $\bar{Z}=r^{-8}$

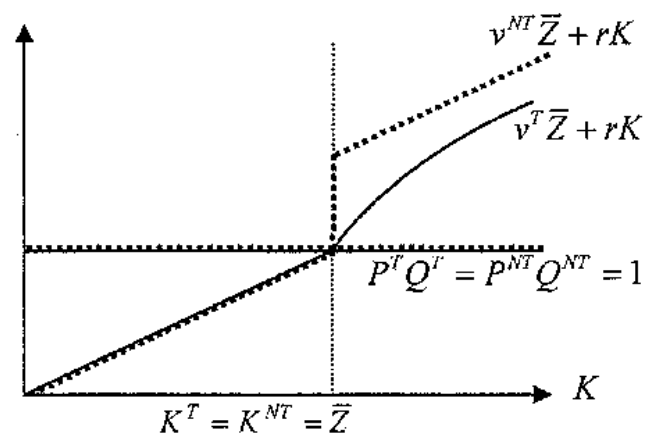

(c) $\bar{Z}<r^{-s}$

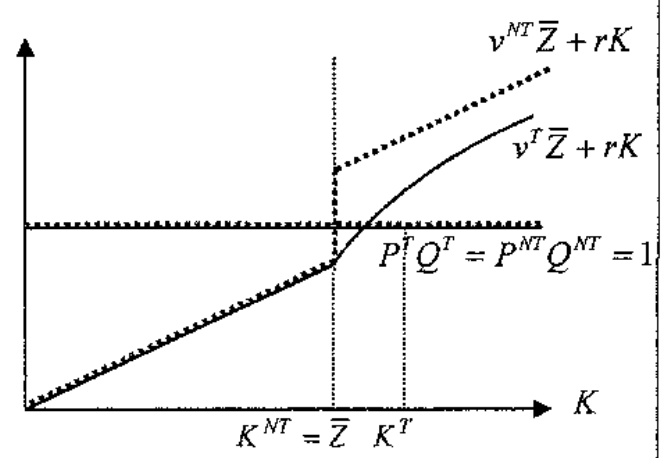




\section{REFERENCES}

Appelbaum, E., and E. Katz, 1986, "Measures of Risk Aversion and Comparative Statics of Industry Equilibrium," American Economic Review, Vol. 76 (June), pp. 524-29.

Batra, R.N., and A. Ullah, 1974, "Competitive Firm and the Theory of Input Demand under Price Uncertainty," Journal of Political Economy, Vol. 82 (May-June), pp. 537-48.

Caballero, R.J., 1991, "On the Sign of the Investment-Uncertainty Relationship," American Economic Review, Vol. 81 (March), pp. 279-88.

Hartman, R., 1976, "Factor Demand with Output Price Uncertainty," American Economic Review, Vol. 66 (September), pp. 675-81.

Haruna, S., 1992, "The Comparative Statics of a Competitive Industry with Free Entry and Uncertainty," Japan and the World Economy, Vol. 4 (November), pp. 239-49.

Judd, K., 1985, "The Law of Large Numbers with a Continuum of I.I.D. Random Variables," Journal of Economic Theory, Vol. 35 (February), pp. 19-25.

Krishna, K., and L.H. Tan, 1999, "Transferable Licenses Versus Nontransferable Licenses: What is the Difference?" International Economic Review, Vol. 40 (August), pp. 785-800.

Morgan, G.R., 1997, "Individual Quota Management in Fisheries: Methodologies for Determining Catch Quotas and Initial Quota Allocation," FAO Fisheries Technical Paper No. 371 (Rome: Food and Agriculture Organization of the United Nations).

Organisation for Economic Co-operation and Development, 1999, Implementing Domestic Tradable Permits for Environmental Protection (Paris).

Pindyck, R.S., 1993, "A Note on Competitive Investment under Uncertainty," American Economic Review, Vol. 83 (March), pp. 273-77.

Sandmo, A., 1971, "On the Theory of the Competitive Firm Under Price Uncertainty," American Economic Review, Vol. 61 (March), pp. 65-73.

Spencer, B.J., 1997, “Quota Licenses for Imported Capital Equipment: Could Bureaucrats Ever Do Better than the Market?" Journal of International Economics, Vol. 43 (August), pp. 1-27.

Squires, D., 1994, "Firm Behavior Under Input Rationing," Journal of Econometrics, Vol. 61 (April), pp. 235-57. 